\title{
Apropos 'Association of suboptimal 25-hydroxyvitamin D levels with knee osteoarthritis incidence in postmenopausal Egyptian women'
}

\author{
Subhash C. Arya $\cdot$ Nirmala Agarwal
}

Received: 11 November 2012/Accepted: 8 March 2013/Published online: 17 March 2013

(C) Springer-Verlag Berlin Heidelberg 2013

\section{To the Editor}

We compliment Abu El Maaty et al. [1] for their meticulous investigations to assess the incidence of vitamin D deficiency in postmenopausal women at the Rheumatology outpatient clinic at the Al-Kasr Al-Aini Medical University Hospital at New Cairo City, Egypt, and concur that randomised control trials are desirable to decide the dose schedules for vitamin D supplementation in postmenopausal women. Nevertheless, it would also be important to carry out comparable investigations at different non-academic, non-research health care centres in different Egyptian regions.

Although all vitamin D estimations (as serum 25-hydroxyvitamin D) at the Al-Kasr Al-Aini Medical University Hospital were carried out employing the 'gold standard' technology of high-performance liquid chromatography method (HPLC), not many hospital or health care centres elsewhere would be equipped to carry out HPLC in their premises. They would have to employ commercially available enzyme-linked immunosorbent assay (ELISA) kits for serum 25-hydroxyvitamin D measurements. A beginning towards an in-house standardisation could be made in individual laboratories by picking up blood samples from cases with a high or level serum 25-hydroxyvitamin D level and to prepare its 20 aliquots. By testing such aliquots repeatedly, it would be possible to work out local mean serum 25-hydroxyvitamin D level and standard deviation (SD) [2].

Vitamin D deficiency is a global phenomenon afflicts about one billion people worldwide [3]. In resource-poor countries, with vast population of masses with vitamin $\mathrm{D}$

S. C. Arya $(\bowtie) \cdot$ N. Agarwal

Sant Parmanand Hospital, Delhi 110054, India

e-mail: subhashbhapaji@gmail.com deficiency, the laboratory infrastructure is poor [4] and it would not be feasible to assay vitamin D level even by ELISA technology. Simpler, point-of-care, rapid tests are needed to quantify 25 -hydroxyvitamin D level levels in the clinicians' premises and in laboratory setup at primary health care centre laboratories.

Last but not least, future plans towards vitamin D supplementation in postmenopausal women in Egypt [1] should include both vitamin D3 supplementation and a watch on post-supplementation vitamin D3 levels. A daily supplementation of 1,000 IU of vitamin D3 may fail to bring levels to a minimum of $75 \mathrm{nmol} / \mathrm{l}$ in $20-30 \%$ cases [5].

Acknowledgments The secretarial assistance of Ms. CG Sherin is acknowledged.

Conflict of interest None.

\section{References}

1. Abu El Maaty MA, Hanafi RS, Badawy SE, Gad MZ (2012) Association of suboptimal 25-hydroxyvitamin D levels with knee osteoarthritis incidence in post-menopausal Egyptian women. Rheumatol Int, Nov 4. [Epub ahead of print]

2. Quality assurance in clinical chemistry: internal quality control. In Kumari S, Sharma KB (eds) Health Laboratory Services in Support of Primary Health Care in South-East Asia Region. WHO Regional Office Publication, South-East Asia Series Number 24, 2nd ed. 1999:123-124

3. Horlick MF (2007) Vitamin D deficiency. N Engl J Med 357: 266-281

4. Nkengasong JN, Nsubuga P, Nwanyanwu O, Gershy-Damet GM, Roscigno G, Bulterys M, Schoub B, DeCock KM, Birx D (2010) Laboratory systems and services are critical in global health: time to end the neglect? Am J Clin Pathol 134(3):368-373

5. Schwalfenberg GK (2010) A step in the right direction. CMAJ 182:1763 